\title{
AGUSTÍN ESPINOSA Y EL "CRIMEN" DE LA ESCRITURA: NOTAS PARA EL ESTUDIO DE SU FIGURA AUTORIAL
}

\author{
Alejandra Acosta Mota \\ Universidad de La Laguna
}

\section{RESUMEN}

Este artículo estudia la figura autorial de Agustín Espinosa desde una doble perspectiva. La primera se centra en el ethos discursivo que construye el escritor entre el final de la década de los veinte y la publicación de Crimen (1934). Mientras que la segunda atiende a las distintas imágenes del autor que sobrevienen a partir de la controvertida recepción de ese libro. Ambas aproximaciones abordan las fisuras y las continuidades entre la figura de Espinosa y las representaciones de la autoría en su época, con el objetivo de poner de relieve la importancia del escritor canario para el estudio del surrealismo en España y los factores socioculturales que han influido en su escaso reconocimiento como una de sus voces más representativas. PALABRAS ClAVE: autoría, paratextos literarios, censura, literatura de Canarias, vanguardias.

\section{AGUSTÍN ESPINOSA AND THE “CRIME” OF WRITING: NOTES ON THE STUDY OF HIS AUTHORIAL FIGURE}

\section{Abstract}

This article studies the authorial figure of Agustín Espinosa from a double perspective. The first focuses on the writer's ethos in texts dated between the end of the 1920s and the publication of Crimen (1934). The second attends to the different images of the author that emerge as a consequence of the scandal surrounding this book. Both parts of this approach deal with the fissures and continuities between Espinosa's image and the representations of authorship in his time, with the purpose of highlighting the relevance of the Canary writer for the study of Surrealism in Spain and the sociocultural factor leading to his scarce recognition as one of its most representative voices.

KEYwORDs: authorship, literary paratexts, censorship, literature of the Canary Islands, avant-garde. 


\section{INTRODUCCIÓN}

En este trabajo abordaré la imagen de autor de Agustín Espinosa, esa figura imaginaria o semblanza discursiva que, construida en el texto literario y en sus inmediaciones, ocupa, de manera casi fantasmagórica, el lugar del productor del mensaje en el acto comunicativo de la lectura ${ }^{1}$. Dado que la imagen de autor entraña una doble naturaleza, en tanto resulta, por una parte, de los esfuerzos del escritor por proyectarse de una determinada manera en sus obras y discursos en general $^{2}, \mathrm{y}$, por otra, de las representaciones que terceros realizan también de él, estructuraré mi análisis atendiendo a esta doble perspectiva. Ambas partes son, sin embargo, complementarias, puesto que una y otra dimensión de la imagen autorial influyen en la percepción que los lectores tienen del signatario de una obra literaria, se retroalimentan y están mediatizadas por el imaginario de su tiempo y por las representaciones estereotipadas de la autoría, que funcionan como modelos susceptibles de ser actualizados, reinterpretados o subvertidos por el escritor y por aquellos que atentan, también, construir su perfil en el espacio público.

En primer lugar, me centraré en algunos de los rasgos más notables de la imagen que construye Espinosa de sí mismo, particularmente en relación con los lenguajes de vanguardia, en varios de sus discursos ${ }^{3}$, a partir de 1928 y hasta la publicación de su libro Crimen, en 1934. Es precisamente en este libro y en otros textos de la misma época en los que el ethos surrealista de Espinosa se nos revela luminosamente y en los que el escritor emerge como uno de los pocos, si no el único, que asumió el surrealismo como una poética propia y determinante en su identidad artística.

${ }^{1}$ El concepto de «imagen de autor» es la extensión, a los estudios de la representación de la autoría, del ethos discursivo, una categoría surgida, a su vez, del cruce entre las perspectivas del análisis del discurso y de la retórica clásica. El ethos no es ni la persona biográfica ni el nombre del autor ni el «autor implícito» de la narratología, es el que cada discurso construye de su signatario y responsable (Amossy 2014: 75-76). La «imagen de autor» puede funcionar como una estrategia de posicionamiento más o menos deliberada en el campo literario, tal como lo definió Bourdeu, por lo que puede entenderse también como «postura» (Amossy 2014: 72).

${ }^{2}$ Los escritores no han sido nunca indiferentes a la propia representación, que los lectores pueden rastrear en sus metadiscursos, incluso cuando la intención sea, como sucede en los casos de Beckett o Gracq, disolver la presencia del sujeto como origen del texto. Las huellas del «autor» se advierten en la propia revuelta que constituye el vacío o la negación. El fin de la autoría y de la autorización se consideran topos de la Modernidad, pero son reveses de modelos necesariamente construidos anteriormente. Cuando Barthes declaró «la muerte del autor» estuvo probablemente influenciado, además de por la novela antihumanista, reaccionaria al realismo literario, por la actitud antiburguesa de las vanguardias (Beresmeyer, Buelens y Demoor 2016: 235).

${ }^{3}$ La imagen de autor puede encontrarse en el más amplio abanico de tipos de textos. Tal como apunta Amossy, «de la misma forma que se puede extraer una imagen de Breton a partir de los manifiestos surrealistas, también se puede extraer una imagen de Breton de los poemas de Signo ascendente o de Nadja» (2014: 70). 
Crimen, la obra que convierte a Espinosa en «el escritor surrealista acaso más valioso y representativo de toda la literatura española» (Pérez Corrales 1986: 515), fue, sin embargo, poco entendida en el momento de su publicación, prontamente censurada y condenada a una existencia semiclandestina. Las razones de este silenciamiento, que ha ensombrecido la figura de Espinosa, residen en el erotismo desbordante del libro y en los prejuicios político-religiosos suscitados por el psicoanálisis y por el temor a la influencia de la cultura extranjera en el público español. Así, en la segunda parte de este trabajo analizaremos la escisión de la imagen de Espinosa, a partir de 1936, como consecuencia de las relaciones entre escritura y moral que afectaron la recepción del libro y la manera en que estas acabaron influyendo la legitimidad de su autor.

Este estudio lo proponemos como un punto de partida o prolegómeno para futuros estudios sobre la compleja figura de Espinosa, que todavía es poco conocida fuera de su tierra natal y que merece ser estudiada en profundidad respecto al campo cultural español y al europeo.

\section{LOS GESTOS DEL ARTISTA: HACIA EL ETHOS SURREALISTA EN CRIMEN}

Según Barthes, el ethos son los «aires» que el hablante se da a sí mismo a través de su discurso; más que "decirse», el ethos se «muestra» o se implica en la actitud del hablante (Meizoz 2004). Uno de los rasgos más acentuados de la obra de Agustín Espinosa es el culto a lo nuevo o a los mitos del naciente siglo xx, el surrealismo ejerce en él su influjo porque se le presenta, precisamente, como una sensibilidad inédita (Pérez Corrales 1986: 89-146). Pero esto no impidió al escritor abrir su conferencia inaugural para la exposición de Jorge Oramas, Media hora jugando a los dados (1933), citando a Baudelaire o discurrir, cuando lo ameritaba, sobre el romanticismo surrealista; en este caso, como en tantos otros, Espinosa demuestra «la complejidad de sus actitudes» (Pérez Corrales 1986: 102), que viene determinada, entre otros elementos, por la fragmentación de la subjetividad y, a la vez, una vuelta rabiosa hacia ella pero desde la óptica surrealista, que en el escritor canario estará ligada a su redescubrimiento de la literatura del siglo XIx. Su ethos discursivo, pues, como en la gran mayoría de los escritores, no es monolítico y puede ofrecer, de un texto a otro, una visión movediza del autor, pero, en sus discursos de final de la década de los veinte y principio de los treinta, puede señalarse un rasgo común: nos remiten constantemente a representaciones novedosas de la autoría o a lecturas polémicas de modelos anteriores, las cuales beben, indudablemente, de los lenguajes de la vanguardia. Incluso en algún texto de carácter más propagandístico que literario, como el redactado para la inauguración de la exposición de Celestino González, en 1928, se advierte ese empuje renovador:

Si algún cartel fonético hiciera falta para etiquetar mis palabras de hoy, ninguno mejor que este: YO CARTEL FONETICO DE UNA EXPOSICION [...] que en mis palabras haya más de anuncio luminoso que de disertación académica. Más de pregonador 
de barraca de feria que de discursista del señoras y señores [...] ¡Adelante, señores! ¡Adelante señoras y caballeros! Vean unos momentos, con los ojos kalidos-cópicos de Celestino González, pedazos rectangulares del Valle de la Orotava (1986: 660-661).

El crítico de arte, en lugar de desvanecerse en disertaciones teóricas, se transforma en uno de los fascinantes objetos del paisaje urbano de la modernidad, el cartel luminoso, para invitarnos a presenciar la «actuación» extravagante de un acuarelista. Tanto el acto inaugural como las obras contenidas en la sala se convierten, entonces, en representación; en performances inesperadas de un crítico y un artista. Espinosa se retrata de manera antiacadémica, con una actitud similar a las gestadas al calor de las vanguardias, que difundirán, con un claro propósito antagonista, nuevos perfiles del hombre de letras. Como muestra, considérense los vasos comunicantes entre el texto espinosiano y esta carta de invitación redactada en 1913 por el poeta Arthur Cravan:

Vengan a verlo - Sala de la Sociedad de hombres de letras - número 8 de la calle Danton - El Poeta - Arthur Cravan - (sobrino de Óscar Wilde) campeón de boxeo, peso $125 \mathrm{~kg}$, estatura $2 \mathrm{~m}$. - El Crítico BRUTAL — HABLARÁ — boxeará - bailará - el nuevo "boxing dance" — el verdadero boxeo CON LA PARTICIPACIÓN DEL ESCULTOR MAC ADAMS — otros números excéntricos. NEgro, BOXEAdor, BaIlarín. - domingo 5 de julio a las 9 pm. Precios de los boletos: 5 F, 3 F, 2 F (apud Meizoz 2013: 254).

Espinosa también entiende la literatura como boxeo, que forma parte del imaginario del deporte, tan importante en su obra como instrumento de destrucción de lo decimonónico, y cuya semántica le sirve para abordar muchos temas, pero especialmente el campo literario como ámbito de conflicto o lucha artística:

En boxing, se dan los dos tipos que la literatura nos ha ofrecido tantas veces: el Lope; el Fernando de Rojas: los mil puñetazos, que culminan en el triunfo más lejano, pero el mismo, al fin; el gran puñetazo único que pare el knock-out (Espinosa 1980: 26).

A diferencia del sobrino de Oscar Wilde, que vivió la bohemia y practicó el boxeo, Espinosa tuvo una formación literaria reglada y siguió una carrera en la enseñanza de la literatura que lo llevó a ocupar cargos públicos como profesor y gestor cultural. Sin embargo, Cravan se convirtió a sí mismo en metáfora para presentarnos, artísticamente, una perspectiva del mundo radicalmente nueva y para pulverizar los estándares tradicionales de la crítica (Jones 2019: 1-8), como él, Espinosa se inscribió a sí mismo como agente antagonista del campo cultural. En «Yo no soy hijo pródigo» (1932), volverá sobre la literatura como juego deportivo en un ataque a lo decimonónico que se burla del modelo de autor profesional que alcanza madurez en ese siglo, es decir, el que escribe para congraciarse con el público o los que imprimen y distribuyen sus obras:

Tras cada acto público, tras cada expresión ciudadana, el habitante de la isla, el "homo canariensis» ve una larga cadena de ruedas, una gran teoría de resortes, 
que casi nunca existen para desgracia del receloso y suerte del actuante [...]. No soy jugador de ningún equipo profesional. No cobro nada por mi juego. Soy «amateur» del más viejo, generoso y mesado deporte: la literatura [...]. Hago hoy -y voy a ganarlo- mi primer partido regional contra el «Futbol Club Suspicacia» (Espinosa 1980: 119-200).

$\mathrm{Al}$ posicionarse en este artículo de prensa como «amateur» de la literatura, Espinosa estaba apelando a un lector específico, probablemente detractor: el «homo canarienses» o el espectador suspicaz. Existe en la escritura de Espinosa una dimensión dialogística que proviene de su fascinación por el prólogo literario, un género de larga tradición en España que nace con las innovaciones de autores que lo elevaron artísticamente, sacándolo de la "oratoria de sobremesa", para convertirlo en "parte inseparable del texto» o en "una especie lateral de la crítica» (Borges 1998: 9-10). El prólogo es el paratexto por antonomasia reservado a la voz del autor y se convertirá en campo fértil de autorrepresentación, pero, a la vez, de desafío de las convenciones que tradicionalmente lo han regido, a través del juego de la ficción. El mismo Espinosa confesó, hacia el final de su vida, que tenía una "prologomanía crónica antigua» (2018: 277) y recibió, probablemente, el influjo de Cervantes, Torres Villarroel y Unamuno, por nombrar solo algunos de los escritores que conocía bien y que se interesaron por las posibilidades expresivas de este tipo de texto en tanto pieza literaria.

Una traición y dos historias es un paratexto de Lancelot, $28^{\circ}-7^{\circ}$ que no llegó a publicarse como prólogo, pero en el que los lectores asisten a un "film documental» del que el propio Espinosa es protagonista y personaje adorado por la cámara, así como también el director o entrevistador. Su irónico desdoblamiento recuerda las conversaciones de los autores de prólogos con amigos que no son más que proyecciones de las propias contradicciones surgidas en el creador durante el proceso de escritura -el del Quijote de 1605 es probablemente el más representativo-y sirve para proponer dos orígenes antitéticos para Lancelot: la memoria o las anécdotas autobiográficas y la más pura experimentación poética del paisaje. Sin resolución ninguna, el sujeto de escritura quedará envuelto en misterio, disuelto en las antípodas irreconciliables: «Adiós, Agustín Espinosa [...] te haré traición y contaré en Tenerife las dos historias» [1929] (Espinosa 1986: 679).

Con la desacreditación del documental y la autobiografía en Una traición $y$ dos historias viene aparejada también la burla hacia el escritor como celebridad, figura carismática, gestada en la cultura de masas, que será conocida tanto por sus obras como por su vida y su intimidad. Hacia este modelo "comercial» de la autoría reaccionaron negativamente autores como Melville, que se rebelaron contra la identificación de estética y moralidad y en cuyas estrategias de evasión la crítica ha encontrado una «intensificación del ideal romántico del Genio, donde el Autor ya no es solo independiente de la sociedad, sino que también la desprecia» (Beresmeyer, Buelens y Demoor 2016: 235).

Espinosa deconstruye más abiertamente las convenciones del prólogo a partir de la irrealidad y el humor que caracterizará su obra más transgresora y surrealista en el preliminar que escribe para la edición de Litoral (1934), el poemario de José Rodríguez Batllori. Quizá su más llamativa extravagancia sea que escribe 
un prólogo en primera persona, como los que acompañan a una obra propia, para comentarla y presentarla al lector, en lugar del de un crítico o amigo que es invitado a encomiar una obra ajena. Su objetivo, de acuerdo con las expectativas convencionales, debería ser insertar el libro de Rodríguez Batllori en su debido contexto o proporcionar algunas guías de lectura; sin embargo, el prologuista se pregunta ¿qué lo obliga?:

¿Por coacción de quién? ¿Del autor? ¿De su amistad? ¿De la mía? ¿De un prefaciomanismo o prologomanismo aprendido en el prologomaniano Unamuno? ¿Por autocoacción? ¿Por qué no ha de existir la autocoacción si existe la autosugestión y el automatismo?

No hay libro, por extraña que sea su clase, que no plantee problemas de soluciones plurales y hasta contrarias (Espinosa 2018: 95-96).

No hay, pues, de acuerdo a este prólogo, «laboratorio de análisis» que valga para abordar críticamente la poesía de acuerdo con Espinosa (2018: 96). Algún comentarista le reprochó que utilizara las páginas preliminares del libro de Batllori para ensalzar, supuestamente, su propia figura (Pérez Corrales 2018: 98), cuando su dramatismo iba encaminado, en realidad, a representar al poeta que no conoce de las imposiciones ni del público ni de la crítica. Lo hace, por ejemplo, al ridiculizar el tópico de la fama, representada a menudo en los clásicos modernos como una empresa peligrosa o atrevimiento y a través de símbolos o mitos que describen una ascensión ${ }^{4}$ :

Si yo fuera otro Dios, mandaría un buen hato de ángeles escoltando la sombra de la osada aventura del poeta Rodríguez Batllori. Pero es que no lo soy. Quédame sońar, desde el astro más alto de mi prólogo - ¿mío o suyo, amigo Rodríguez Batllori, de su libro?-, que el que todo lo puede hará realidad -única, plena y rauda- lo que es únicamente personal y generoso deseo (Espinosa 2018: 97).

Es pues Espinosa, como ya ha apuntado Pérez Corrales, un «prologuista inequívocamente antiacadémico, opuesto al vacuo eruditismo de manuales y enciclopedias y a toda la crítica biográfica, bibliográfica y anecdótica» (1986: 214). De ahí, creo, que aparezca el can como una presencia fantasmal detrás de las coacciones del poeta, esas «secretas, buidas, escondidas, hijas de perra que muriera aullando a las estrellas su parto» (Espinosa, 2018: 95). La imagen del perro que ladra a la luna montada en su carro de estrellas la recoge Alciato en su emblema 164. El can ve su reflejo en el brillo celestial y cree que un animal idéntico a él le mira mientras le lanza una ofensa, en su vana y narcisista confusión no sabe hacer otra cosa que

${ }^{4}$ El vuelo de Ícaro, Faetón o del águila o el fénix son típicos en este tipo de representaciones clásicas del reconocimiento público del poeta. Algunas veces incluso son sus pensamientos o sus versos los que emprenden el vuelo. 
ladrarle de vuelta. Ya Juan de Robles, en El culto sevillano ${ }^{5}$, al comentar el emblema lo ponía como ejemplo de los «censores que no son ni pueden ser críticos, sino impertinentes, porque sólo pretenden dar a entender que saben, y no se estiende su jurisdición a más que notar un vocablillo improprio o un modo de hablar no muy usado» (2015: 656). La visión de Espinosa sobre la crítica no solo pasaba por el desdén hacia cualquier tipo de exhibicionismo erudito, sino que era partidario de una crítica de corte impresionista, en la que el análisis de los textos desde una perspectiva pretendidamente científica es incompatible, tal como se desprende su texto Tiento y análisis (1934).

Esta actitud retadora y polemista, opuesta a un lector escéptico, quizá cerrado a los discursos artísticos que van a contracorriente, tomará nuevas dimensiones al mezclarse con el humor negro, desbordante y provocativo de la prosa surrealista. En Gestos del idioma. A propósito del "Cagatintas» (1934), Espinosa define la escritura como un acto irreprimible, regocijante y escatológico que tiene lugar en el sujeto, en la frase y en la página: «QQué hago en este momento sino deponer, para ti, lector, propia y generosa tinta; tinta que no puedo detener, porque ella fluye, lector, por sus legítimas cuenta y riesgo, cada vez que quiero decirte algo?» (Espinosa 2018: 75). El autor nos presenta aquí, aunque de manera violenta y juguetona, una "fisiología» $\mathrm{o}$ "anatomía del estilo» en términos similares a los utilizados por Flaubert, que describe la «literatura» como una «... comezón permanente! Es como una ampolla en el corazón. Me duele sin cesar, y la rasco con alivio» (apud Durand 2014: 115-116). Ese espectáculo que se logra a través de la gestualidad y el cuerpo resulta aquí, por su naturaleza íntima y humana, paradójicamente, mucho más excéntrico que el boxeo. Un poco más tarde, ese mismo año, en el recuerdo que le dedica a su profesor Baltasar Champsaur, Espinosa insistirá en esta idea de la escritura a través del cuerpo, donde el autor recuerda al maestro mientras «corre su pluma, diríase que autónomamente, por riesgo y cuenta propios, sobre las virginales cuartillas» (Espinosa 2018: 79).

La fatalidad y la radicalización de la subjetividad serán aún más desbordantes en Crimen y en otros escritos de esta época, Espinosa nos dibujará también este ethos o actitud de factura indudablemente surrealista. Se definirá como «alcantarillero de sueños adversos» (Espinosa en Pérez Corrales 1986: 518) y en Diario espectral de un poeta recién casado (1932-1933) nos ofrecerá este autorretrato:

Al autor de este diario le gusta registrar cotidianamente-aunque no lo haga público siempre- horas y gestos que nadie escucha, signa ni atiende. Le gusta enredar diariamente sus ojos en la sobrerrealidad de los humores del mundo; en las vibraciones extrańas y en los astrales laberintos que llevaron a una generosa locura al poeta neoyorquino Edgar Allan Poe [...] Cambian las costumbres y los afanes de los hombres: Pero algo hay que permanece inmutable a través de cataclismos, eras y

5 Es una obra del xvir donde el autor intenta definir las características del hombre «culto», en el que puede rastrearse el origen del concepto de «crítica moderna» en España. 
tiempos: el fondo o substrato poético, irracional - «Subconsciente», diría S. Freudde la vida (Espinosa 1980: 185).

El surrealismo trasmuta, pues, en Espinosa, la alegría y el juego vanguardistas en pasión y sueño, misterio e introspección. Eran parte de su poética surrealista el imaginario del subconsciente y las técnicas irracionales de creación. Es sumamente llamativo que mientras Espinosa se afirma de esta manera, otros poetas de su época, celebrados por su acercamiento al surrealismo, admiten que no estaban interesados en el misterio, la oscuridad o el automatismo. Lorca manifestaría en 1929 que sus poemas los ha escrito «con una tremenda lógica poética. No es surrealismo, ¡ojo!, la conciencia más clara los ilumina» (apud Havard 2001: 33); Vicente Aleixandre también aclarará que «no he creído nunca en lo estrictamente onírico, en la "escritura automática", en la abolición de la conciencia creadora. Pero he de confesar la profunda impresión que la lectura de un psicólogo [Freud] de incisiva influencia me produjo en 1928" (apud Havard 2001: 35); y Rafael Alberti coincidirá con ellos en esta cuestión al referirse a su libro Sobre los ángeles como «poesía de atmósfera surrealista, no poesía surrealista, porque la poesía surrealista francesa tenía sus reglas y sus reglas oníricas [...]. A mí me interesa dentro de lo oscuro ser claro» (apud Havard 2001: 35-36).

Pero centrémonos, ya, en este punto, en la obra cumbre de Espinosa. La voz poética de la narración de Crimen es la de un asesino letraherido que, al escribir, recrea el desordenado y caótico relato de una pasión desenfrenada y la muerte violenta de la mujer deseada, vistos a través del prisma de una conciencia en vías de desintegración. El narrador oscilará entre la primera y la tercera persona, siguiendo una temporalidad estacional, climática; hilvanando sueños, pesadillas y recuerdos; disolviéndose, extrañándose, también, a través de la más depurada poética surrealista, en la subjetivación de los objetos. Pero algunos fogonazos metadiscursivos desvelan un sujeto de escritura que aporta unidad y dramatismo al libro. En el primer fragmento, se advierte cuando el narrador en tercera persona cambia a la primera y, asumiendo el registro epistolar de un prólogo literario, se dirige a los lectores incapaces de tener una sensibilidad comparable a la suya hacia el «caso» o «crimen cometido». El asesino advierte que aquellos "que no habéis tenido nunca una mujer de la belleza y juventud de la mía, estáis desautorizados para ningún juicio feliz» (2018: 11), asumiendo un registro similar al de Torres Villarroel ${ }^{6}$, autor libérrimo e irreverente, cuando desacreditaba a sus detractores en el prólogo a las Visiones y visitas con Don Francisco de Quevedo por la corte, por ser incapaces del acto de la escritura: «Yo quedo burlándome de verte metido a corrector de autores y libros y dando voto decisivo en lo que no entiendes ni puedes ejecutar» (1966: 13). Hacía también Torres, por cierto, en ese prólogo otra afirmación violenta de la subjetividad que probablemente resultó atractiva a Espinosa: «Desde hoy empiezo a soñar. Ten paciencia o ahórcate» (1966: 12).

\footnotetext{
${ }^{6}$ Torres es uno de los escritores a los que Espinosa dedica atención en varios textos críticos y literarios.
} 
Las referencias en la prosa de Crimen a otros textos del autor nos remitirán también al sujeto de escritura, así como la irrupción de Poe, Larra, Espronceda o Bécquer en las oníricas recreaciones del asesino, fascinado por la literatura más subversiva del siglo pasado, y el «Epílogo en la isla de las maldiciones», donde habla el «Yo, el hijastro de la isla. El aislado» (Espinosa 2018: 55).

El surrealismo será, pues, un horizonte de experimentación que dará un nuevo cariz a una de las obsesiones literarias que ya existían en Espinosa y por la cual ya era conocido: polemizar el statu quo de la creación literaria y artística. Esto fue, en gran parte, lo que convirtió a Crimen en un libro peligroso. Como apunta Isabel Castells, la prosa surrealista de Crimen resultó provocadora porque se ponía «al servicio del humor negro y de la belleza convulsiva, unidos para subvertir los valores que tradicionalmente se asocian a la creación artística» (2019: 12). Pero también fue clave que las escenas de violencia, mutilaciones, canibalismo, prostitución o infanticidio que tienen lugar en el mundo del asesino no encontraran, como en los relatos tradicionales, una resolución aleccionadora (Castells 2019: 13).

El ethos surrealista en Crimen tendió, para algunos lectores, un puente entre escritura y moral, fundamentalmente a través del rechazo a la expresión artística de lo individual reprimido, representado en el mundo de los sueńos y de la sexualidad. Puede verse, de manera luminosa, en los comentarios que le dedica al libro un reseñista de El defensor de Canarias que no oculta su nerviosismo ante las implicaciones de que la lectura de Crimen nos instale en una psique capaz de alojar imágenes tan crudas:

Tal vez se intente pensar que este «Crimen» lleva unidad subyacente. Siendo producto de un sueño, tal concepto pudiera ser un recurso salvador; pero, entonces, la unidad solo estaría en la psique del autor [...]. El que quiera vivirla tiene que sońarla. Y quién se mete en estos sudores psíquicos para sentir que el olfato se le llena de excremento de perro y alguna otra sugerencia desagradable del trasmundo sońado?

Soñar, sí. Pero soñar despiertos, con claridad de luz y claridad de conceptos; donde lo sońado tenga la satisfacción de lo sublime. Hacer otra cosa es afición de exhibirse (apud Pérez Corrales 1986: 487).

Espinosa se inscribió en su obra con muchos trajes: el del prologuista, el amateur, el atleta literario, el director de cine, el diarista... Pero el más elusivo de todos, el asesino pasional, será el que le ganará el repudio público como autor. Algunas partes del libro que habían sido publicadas sueltas, con anterioridad, en revistas y periódicos, en ese momento, ya habían aparecido con parte de su vocabulario censurado (Pérez Corrales 2018: 308), más leña al fuego añadirían, probablemente, el prólogo y la portada del libro, acaso lo único que llegarían a ver y leer los que, aun sin tener el más mínimo interés en la obra espinosiana, se lo llegaran a encontrar. Solo en esos preliminares ya estaba, después de todo, enlodada en la psique de un personaje que a veces nos parecería un escritor, una muestra de las imágenes que pueblan el libro y que desafían las conductas sexuales heteronormativas. El erotismo del libro, que un escritor fuera capaz de imaginarlo y de, encima, presentarlo al público desde la insolencia del romántico, del escritor genial que desprecia la sociedad, será precisamente lo que saldará su censura. 


\section{ESPINOSA Y EL “CRIMEN» DE LA ESCRITURA}

[...] el Olimpo ya no es la mansión de los dioses alegres, ni Cristo que lo fundó; ahora, a un poeta, aunque sea un dios, le piden la cédula de comunión o un ejemplar de la Biblia sin notas, según los gustos. La castidad ha matado a la inocencia. Leopoldo Alas, "Clarín», Apolo en Pafos, 1887.

Poco tiempo después de la publicación de Crimen, algunos críticos, como Ricardo Gullón, se aproximaron al libro con una perspectiva que confirmaba esta lectura: «El crimen, un crimen, puede ser el pretexto para engarzar las más jocundas metáforas, sagaces observaciones que adquieren repentinamente un fuerte brillo de certeza" (apud Pérez Corrales 2018: 287). Pero el libro recibió también un aluvión de críticas negativas que oscilaron desde una lectura miope hasta las acusaciones más incendiarias. Para Ángel Lacalle, el libro «es fruto de las aficiones superrealistas del autor. Más interés ofrece su primer libro, Lancelot, $28^{\circ}-7^{\circ}$ " (apud Pérez Corrales 2018: 316). En la reseña de Sobre el signo de Viera aparecida en Madrid, en la Revista Hispanoamericana de Ciencias, Letras y Artes, se arguye de Espinosa que «no todos sus ensayos nos merecen la misma consideración. Hay en este escritor estimable una gran desorientación» (apud Pérez Corrales 2018: 319). En otras ocasiones, como ha demostrado Pérez Corrales en su amplísimo estudio acerca de la recepción de la obra de Espinosa a partir de 1936, el libro prácticamente desaparece del vocabulario de algunos críticos (2018: 341-342). Pero son las acusaciones formales, en 1937, de la Comisión Depuradora de Instrucción Pública, de que Espinosa había escrito un libro «inmoral» (Pérez Corrales 2018: 330) las que tuvieron una especial repercusión en su carrera literaria y en su integridad personal.

Tan pronto como en abril de 1935, Espinosa se encuentra ya defendiéndose de la sospecha que se cierne sobre él, en un artículo que escribe sobre el escándalo que había causado la proyección en Canarias de La edad de oro afirma: "Se han pronunciado con excesiva frecuencia las palabras "pornográfico", "libre", "procaz" [...] con relación a La Edad de Oro, ni con más ni con menos razón -puedo decirlo ahora de paso- que a propósito de mi libro Crimen» (Espinosa 2018: 120). Debió resultar excesivamente chocante a Espinosa que su libro fuese calificado de "pornográfico", puesto que ese término se reservaba para las producciones que quedaban fuera de cualquier tipo de arte, incluso el más comercial o popular. De ahí que en el primer tercio del siglo xx se inventara un término pseudoerudito para nombrar todo lo erótico y pornográfico como "sicalíptico" (Zubiaurre 2014: 17). La pornografía la entiende Ortega y Gasset también como antítesis del verdadero arte, el mismo Espinosa cita su opinión al respecto en el artículo de 1933 «Notas de un espectador enojado», a propósito de una crítica al cine sentimentalista:

Todo estilo artístico que vive de los efectos mecánicos obtenidos por repercusión $\mathrm{y}$ contagio en el alma del espectador es naturalmente una forma inferior de arte. El melodrama, el folletín y la pornografía son ejemplos extremos de una producción artística que vive de la repercusión mecánica causada en el lector (1980: 219). 
Reaccionaba Ortega, en este sentido, igual que Marañón, hacia la impresionante cantidad de materiales eróticos que, en la época, aparecían en las colecciones de novela corta erótica, en revistas picantes o postales y fotografías, procurando imponer cierto control, desde la cima de la alta cultura, a una corriente popular que se aproximaba a los temas sexuales de manera desinhibida y a veces solapadamente afín a lo feminista y lo gay (Zubiaurre 2014: 14).

Como unos de los firmantes del Manifiesto publicado en Gaceta de Arte, el 18 de junio de 1935, para defender la película de Bunuel, Espinosa apelará, precisamente, a la legitimidad de las influencias intelectuales de la obra, recalcando que se trata de «una aportación documental a la moderna psicología dentro de un ambiente de formas poéticas, y en donde se valoran la teoría de los sueños de Freud, los complejos colectivos de Jung y la moral sexual de Ehrenfels» (Espinosa 2018: 119-120). Pocas repercusiones habrían tenido estos alegatos en la opinión pública, si tenemos en cuenta que la medicina, el influjo de Freud y las pseudociencias habían hecho posible sacar la sexualidad de los límites del confesionario y daban carta de naturaleza a lo que no era heteronormativo (Zubiaurre 2014: 81). $\mathrm{Al}$ ya citado reseńista de El defensor de Canarias las filiaciones de Crimen con estos registros de la desviación no se le habían pasado por alto cuando lo definió como un "cóctel» de "principios físicos, principios psíquicos, neurosis, patología, reflejos, hormonas, cultura, lecturas, jean cocteau y el cubo de la basura» (apud Pérez Corrales 1986: 485-486).

En las tres primeras décadas del Xx se esbozan, en efecto, dos Españas, una «visible» y dominada por la alta cultura y otra «fantasmal», a la que contribuyeron tanto la izquierda como la derecha, ignorada por los historiadores del arte y la literatura, de la que forma parte la ingente producción erótica de esos años, a excepción, de acuerdo con Zubiaurre, de un erotismo de carácter elitista y de poca difusión, representado en buena parte por las vanguardias pictóricas (2014: 81). El libro de Espinosa parece ser una doble excepción, puesto que ¿a qué otro erotismo podríamos adscribirlo sino a ese que entronca con los pintores vanguardistas?

La cubierta de la primera edición de Crimen la realizó Óscar Domínguez. La crítica ha señalado que se trata de una imagen de «aire metafísico y surrealista» que "no es de lectura fácil» (Bonet 2011: 104). Sin embargo, no escapará al observador atento el hermafroditismo de la figura que flota a la izquierda, como una nube esbelta y delicada, o la posición sugerente de la mano cercenada del cuerpo que descansa sobre un tumulto y que acerca los dedos a un orificio, aunque guarde relación, como ha apuntado Hernández Gutiérrez, con el capítulo "La mano muerta», en el que Espinosa vuelve sobre este tema recurrente de la pintura y de la poesía surrealista. Se trataba, pues, en palabras de Bonet, de una «cubierta muy adecuada para un libro de alto voltaje erótico» (2011: 106). Domínguez realizaría también una vińeta para la portada de Romanticismo y cuenta nueva, de Emeterio Gutiérrez Albelo, en la que se nos presenta una figura que tiene por genitales una línea oblicua, cortando otra larga que divide en dos el rostro y el cuerpo. Ambos trabajos los firmaría como "Óscar X» (Bonet 2011: 104) y por esa época realizaría también para el libro Le grand ordinaire (1936), de André Thirion, en un ambiente semiclandestino de «contrabando intelectual», ilustraciones sexuales más crudas (Durozoi 2011: 292). 
La ambigüedad sexual y la androginia se hacían presentes en el arte y la literatura como en las calles de los principales centros urbanos, los escenarios de los teatros, los documentos de la sexología importada e incluso en las eruditas reflexiones de la inteligencia española (Zubiaurre 2014: 390). El travestismo fue uno de estos comportamientos repudiados ${ }^{7}$ que un lector podía encontrar en una revista picante, pero también en La mujer vestida de hombre (1926), de Ramón Gómez de la Serna, o en Crimen, donde aparece un cadáver ataviado con la indumentaria de la víctima:

Tenía aquel hombre un ojo medio cerrado [...]. Tenía la cabeza recién afeitada, y cubría únicamente su ya macabra humanidad un abrigo de señora, impecable, sin una sola arruga, abrigo de maniquí de escaparate de sastrería, demasiado largo para el muerto, al que solo dejaba en libertad los pies. El abrigo llevaba cosido aún en un costado un papel donde se leía: «Ma A., soltera, de 16 años, desconocida» (Espinosa 2018: 21).

Lo cierto es que el erotismo de factura elitista y el de factura popular, aunque diferían en sus lenguajes, compartían temas e influencias y los ya nombrados son solo algunos. Estaban allí también, acechando a los higienistas, los artefactos tecnoeróticos como la mujer ciclista, icono sexual con el que Domínguez ilustraría el poemario de George Hugnet La hampe de l'imaginaire (1936) (Letaillieur 2011: 147), pero que era también recurrente en la sicalíptica finisecular (Zubiaurre 2014: 283). Dado que en el primer tercio del siglo xx estaba extendida la creencia de que el vicio y la inmoralidad eran males que llegaban de fuera, el estereotipo de la bicicleta erotizada arribó a la Península dotado de un fuerte acento extranjero (Zubiaurre 2014: 263). En Crimen, Lucinda la Niña ciclista será, precisamente, un signo de transformación de las islas a través de la llegada de una nueva sensibilidad hacia la belleza convulsiva:

No tiene que ver con «Nikes» [de Samotracia] ni con «Primaveras» [de Boticelli]. Lucinda es, únicamente, Lucinda. La Niña ciclista. La ganadora de todos los combates ciclísticos. La primera filmadora de la verdadera película de las Islas Canarias. La que mis manos nigrománticas saludan hoy (Espinosa 2018: 2016).

Crimen es un libro que dialoga con toda esa producción erótica subterránea, pero ampliamente difundida, que ponía nerviosos a muchos grupos sociales. La prueba está en que, en el prólogo, el narrador disfraza a María Ana de «Miss Equis [...] para desnudarla de algún modo de su andalucismo moreno» (Espinosa 2018: 12). En la cultura erótica visual y popular, las mujeres modernas convivían con las majas y las gitanas de la vieja estampa; revistas como Muchas gracias mostraban a esas mujeres de cabello y ojos negros para promover un sexo patriótico, donde abun-

7 Incluso entre los intelectuales más progresistas se podía encontrar un recelo hacia la costumbre de utilizar atuendos propios del sexo opuesto, puesto que se le atribuía un efecto perjudicial en el desarrollo «natural» de la sexualidad (Zubiaurre 2014: 278). 
daban las mantillas (Zubiaurre 2014: 296). De ahí que la pornografía visual persiguiera «el objetivo doble y contradictorio de modernizar y europeizar a la "castiza", y de hispanizar -a fuerza de volverla reaccionaria y sexualmente conservadora- a la "moderna”" (Zubiaurre 2014: 295).

Con todo, la Comisión Depuradora de Instrucción Pública, dado el estado del campo cultural en la época, no tuvo difícil su tarea en lo que a Espinosa se refiere. La Asociación Católica de Padres de Familia incluso afirmará que Crimen es una novela "completamente naturalista e inmoral» (apud Pérez Corrales 2018: 330), confundiendo géneros a partir de los prejuicios generalizados hacia el erotismo.

La transgresión de Espinosa resultó tanto más insultante, creo, debido a la actitud desafiante hacia la sociedad que caracterizaba a menudo el ethos de sus discursos y que podríamos asociar con los románticos más libérrimos. El siglo XIX había tendido en el espacio público toda una nueva serie de preocupaciones en torno a la integración de los escritores en la sociedad, la utilidad de su oficio y el establecimiento de un código deontológico todavía por determinarse. A propósito de estas contradicciones y de sus relaciones con la moral había publicado un artículo, en el diario $A B C$, José María Salaverría. En ese texto de marzo de 1928, analiza brevemente el estatus del escritor genial a partir de dos casos ejemplares, para plantearse hasta qué punto las credenciales de novelista, poeta o artista eximen a los individuos de que sus actos contrarios a la moral vigente tengan consecuencias: el de Benvenuto Cellini, afamado orfebre renacentista y presunto asesino al que conceden un salvoconducto gracias al papa, que adoraba sus magníficas joyas, y el de Anatole France, retratado por su secretario Jean-Jacques Brousson, en Anatole France en pantoufles (1924) e Itinéraire de Paris à Buenos-Ayre (1927), como «verdadero canalla [...] bajamente libidinoso, ingrato, falso, avaro, desleal, mentiroso, plagiario", para la indignación de sus admiradores (Salaverría 1928).

Los casos como el de Cellini, dice Salaverría, serán si no imposibles muy escasos en una sociedad moderna. Entre Cellini y France, se encuentran otros dos casos de genialidad provocativa y al margen de las normas, el de Byron y el de Espronceda -escritor, como ya apuntábamos, muy admirado por Espinosa-, que se le presentan como improbables, no solo porque entre los ricos ya no se ven aptitudes para la buena poesía, sino porque el escritor, «desposeído ya de melenas, barbas, chalinas y demás agregados peculiares, va entrando en el régimen social común, en las disciplinas corrientes [...] es un hombre a sueldo, a jornal o a destajo, no se le consentirá la postura de niño mimado» (1928). Pero ¿pueden realmente la genialidad y la honradez convivir? Esta es la pregunta que le asalta al considerar la «posición moral» de Anatole France:

Puesto que uno ha leído todos los libros y ha penetrado el secreto de todas las doctrinas y todas las civilizaciones; puesto que se conoce cuánto hay de contradicción y de fugacidad en las ideas que sobre el mal y el bien han mantenido los hombres a lo largo del tiempo, es inútil intentar construirse una moral firme; al hombre superior, según esto, le conviene extraer de la vida todo lo que ella puede dar, sin hacer caso de las arbitrarias restricciones que imponen el honor, la costumbre popular y el vulgo burgués (Salaverría 1928). 
No parece que haya todavía una respuesta demasiado clara sobre las implicaciones de la profesionalización de la escritura como imposición de toda una nueva serie de normas al escritor, pero es desde luego una preocupación muy viva entre los intelectuales, y la conclusión a la que llega Salaverría es que, aunque al escritor genial se le haya bajado de su pedestal simbólico y se le haya despojado de sus privilegios aristocráticos, es un individuo que será vigilado:

¡Qué difícil hacer de él un proletario tranquilo! Porque sabe demasiadamente bien que por su talento, de una singular agudeza [...] tiene en su pluma un aparato de la mayor precisión y al mismo tiempo de lo más peligroso, fino y sutil, terrible cuando quiere, o encantador de fieras y brutos (multitudes) cuando se lo propone (Salaverría 1928).

A Espinosa lo tachará burdamente de niño mimado, por el épater le bourgeois que destilaba Crimen, un anónimo comentarista de Índice Literario, que le hace un retrato ridículo y le adjudica el atrezo del poeta decimonónico, en un texto y una caricatura:

Escribe bien cuando se lo propone el Sr. Espinosa; pero lo que se propone no es eso [...]. Cuando el Sr. Espinosa trata de aterrar a las fuerzas vivas de la Gran Canaria con excesos de lenguaje, no hace cosa distinta que ponerse un frac azul o enfermar del pecho. Mírese Espinosa en este espejo que le ponemos delante y sea el primer asustado (apud Pérez Corrales, 2018: 308).

En esta misma reseña, se admite, sin embargo, que Crimen es un libro que demuestra el talento de Espinosa y su capacidad para producir una obra «verdadera» o, lo que es lo mismo, «legítima»:

Esas fantasías nos descubren a un escritor que sabe su oficio, y puede hacer de su ministerio o milicia cuanto se le antoje. ¿Qué prefiere, por ahora, irritar a sus paisanos con expresiones impronunciables? Él es dueño de sí y hace de su capa un sayo [...]. Esas frases no levantan polvareda bastante para oscurecer a nuestros ojos las cualidades de escritor con que Espinosa cuenta para hacer obra verdadera (apud Pérez Corrales, 2018: 308).

En el poder de influencia que se le atribuye al escritor genial se encuentra también su revés, el temor a que utilice su talento para lograr objetivos opuestos a los grandes centros de poder político. Se trata de la vieja "propiedad penal» que ha señalado Foucault como una de las más antiguas funciones del autor en el texto y que surge con las instituciones especialmente diseñadas para perseguir y condenar a los autores (1984: 8). Llegado el estallido de la guerra civil, ¿suponía Espinosa, escritor genial, un peligro para la derecha sublevada? Lo cierto es que, en materia de política, «toda su posición al respecto está plagada de contradicciones y muestra una evidente debilidad ideológica» (Pérez Corrales 1986: 273). Pero el clima hostil que se había formado en torno a Crimen y la Exposición Surrealista, que Espinosa había ayudado a organizar, lo empujó a asumir públicamente una postura que no dejaba espacio para la ambigüedad, declarándose «unido» al «movimiento salvador 
de España» (apud Pérez Corrales 2018: 325). No duda Pérez Corrales, al realizar una extensa revisión de testimonios y documentos de la época, que Espinosa podría haberse «adaptado inicialmente al nuevo régimen», pero que «de no haber mediado las circunstancias atroces que se dieron, no se hubiera adscrito nunca al falangismo» (2018: 326).

Sin embargo, su esfuerzo inicial por construirse una nueva imagen que lo mantuviera lejos del paredón resultó insuficiente, puesto que la etiqueta denigratoria de la pornografía seguía pesando sobre él, tal como se aprecia en el artículo que aparece en el periódico Acción, titulado «Ayer lo vi con la camisa azul»:

¿Puede alguien creer que se nos haya podido olvidar la sensación desagradable que nos produjo la lectura de aquellos párrafos llenos de vulgar sensualismo, de groserías inaguantables, repletos de los refinamientos más bajos, descubridores de instintos sensuales, perversos? (Giar, en Pérez Corrales 2018: 327).

Producir una obra pornográfica es una de las transgresiones reguladas durante siglos por la moral y, llegado el momento, también por las leyes, que ha resistido, incluso hasta el día de hoy, los cambios históricos, el empuje hacia cualquier tipo de emancipación social de la literatura y el arte o la mutación de los criterios de legitimación del autor, como lo sería, en un determinado contexto, la adhesión a una ideología política. Como afirma Marilyn Randall, «rarely, these days, is "literary" discourse (as apart from scientific or political discourse) granted the kind of potential power that causes its effects to pass from the symbolic to the realm of the "real" world. Pornography is a notable exception; plagiarism may be another" (Randall 2001: 25).

A partir de que Agustín Espinosa escapa de las posibles sanciones, que suponían su despido como docente y la imposibilidad de volver a ejercer su profesión, dejando en la más completa desprotección a su familia, escribe alrededor de 40 artículos para Arriba España, Falange y Amanecer. Algunos de ellos se publican sin firma, o con pseudónimos como Justo Erenas y Adanur (Izquierdo 2019: 109). Espinosa, al que le gustaba convertirse en personaje de sus artículos y que acostumbra firmar con nombre propio, a partir de 1936 empieza a recurrir al ocultamiento de la identidad. La escisión de su figura de autor se extiende también, por supuesto, a otros aspectos más complejos. Para Pérez Corrales:

Su variopinta, versátil obra anterior -modelo de desparpajo, genio, desafío y libertad- da paso a una obra monolítica y funérea. El escritor polémico hasta consigo mismo, como decía Elfidio Alonso, ya no escandaliza a nadie, sino que dice lo que el poder espera que se diga [...] en «Hermana Portugal» y artículos sucesivos es Falange quien lanza sus proclamas panfletarias a través de un Agustín Espinosa vampirizado (2018: 326).

Algunos estudiosos han querido, por el contrario, hallar una suerte de «continuidad ideológica» en toda la obra espinosiana. Gómez Gutiérrez encuentra coherencia en el nacionalismo, que identifica como uno de los leitmotivs de los posicionamientos públicos de Espinosa a través de la prensa, en su reincidente interés por 
el mito de España y la retórica belicista, así como en la relación amistosa y afinidad intelectual con Ernesto Giménez Caballero, autor vanguardista cuya obra se caracteriza por la "tentativa de politizar la rabiosa contemporaneidad del movimiento (que para él concluirá en una adhesión absoluta y precursora al fascismo)» (Mainer en Moreno Caballud 2010: 430). Sin embargo, las posturas reaccionarias o revolucionarias son comunes no solo a Espinosa y a Giménez Caballero, sino a muchos de los autores que desarrollaron su actividad antes de 1936, es por esto por lo que, para Pérez Corrales, igualar los escritos falangistas con «su obra de los tiempos de libertad» conduce a una "confusión de valores» similar a la que ocurre respecto a las figuras de Dalí, Eluard o Aragon (2018: 330). Con todo, el punto de quiebre de la autoría antes y después de 1936 se le presenta, además de por criterios literarios ${ }^{8}$, por la vulneración de uno de los más antiguos axiomas de la literatura como oficio autónomo: el de la autoridad del sujeto de escritura, de ahí que se decante por que los textos falangistas se lean en una edición que los contextualice debidamente, tomando en cuenta que el origen de esos discursos es, en realidad, una maquinaria ideológica; alguno podría haber formado parte, por ejemplo, de la antología clásica de la materia, Falange y literatura (1971), de José Carlos Mainer (2018: 338).

La represión que sufrió Espinosa ha proyectado una sombra larguísima sobre su producción. Ha estado injustamente ausente no solo de libros como Falange y literatura, sino también de la historiografía dedicada al surrealismo en España, aun habiendo escrito la que probablemente sea su obra más representativa. En el estudio de Harvard que citamos aquí y que estudia el ethos surrealista en España no se le nombra ni una sola vez, por ejemplo. No nos consta, tampoco, que la crítica que se ha dedicado a recuperar la abundante producción erótica española de principios del xx se haya acercado a Crimen.

\section{CONCLUSIONES}

El ethos que construye Espinosa a final de los años veinte y principio de los treinta bebió de los aspectos más transgresores de la actitud romántica, de las autorrepresentaciones polemistas de las vanguardias y de la violencia, el humor y el sentido trágico del surrealismo. El más acentuado rasgo que podríamos asignarle sería la reivindicación de la libertad creativa. Así lo retrató con acierto, en 1935, Emeterio Gutiérrez; como un magnífico deportista que corre con seguridad «en un auto lanzado por las más rizadas pistas»; «El traje que Espinosa utiliza en estas correrías», dice, «ha sido confeccionado en los mejores talleres clásicos. No obstante,

${ }^{8}$ Pérez Corrales define la obra de Espinosa posterior a 1936 como «de circunstancias que muy poco tiene que ver con su dinámico vanguardismo -aunque emane de ciertas lamentables ingenuidades futuristas y absolutamente nada con su conexión con el surrealismo-; esta obra de los años 36-38 rompe con evidencia la unidad que caracteriza al resto de su producción» (1986: 6). 
su "daemonium" se agita en las más profundas simas del romanticismo» (Gutiérrez Albelo en Espinosa 2018: 281).

Al hacer apologías de la libertad creativa, Espinosa representaba una abolición, si bien estrictamente simbólica, de cualquier tipo de norma social frente a la supremacía de la literatura y esto lo convirtió a todas luces en un escritor peligroso a los ojos de los lectores más conservadores. Que un escritor de su calibre se atreviera a publicar una obra de erotismo desbordante como Crimen proporcionó los ingredientes perfectos para su emboscada y posterior juicio público. Dada su prominencia en el campo cultural de Canarias, su reconocido talento y su condición de funcionario público, no es extraño que el magisterio español persiguiera robarse, recuperando las palabras de Salaverría, su «instrumento para encantar fieras», el cual pusieron al servicio del falangismo.

Las transformaciones culturales y las maneras en las que estas se representan comportan diferentes significados y acarrean efectos igual de variados para las personas, según las posiciones o identidades sociales que asuman, y en el caso de Espinosa el más sangrante sigue siendo la oscuridad que todavía rodea, en el contexto español y europeo, su importante contribución al surrealismo.

RECIBIDO: septiembre de 2020; ACEPTADO: noviembre de 2020 


\section{BIBLIOGRAFÍA}

Amossy, Ruth (2014): «La doble naturaleza de la imagen de autor», en Juan Zapata (comp.), La invención del autor. Nuevas aproximaciones al estudio sociológico y discursivo de la figura autorial, Medellín: Universidad de Antioquia, 67-83.

Beresmeyer, Ingo; Gert Buelens y Marysa Demoor (2016): «La autoría como performance cultural: nuevas perspectivas en estudios autoriales», en Aina Pérez y Meri Torras, Los papeles del autor, Madrid: Arco Libros, 205-242.

Castells Molina, Isabel (2019): «Crimen, un sueño en libertad», en Daniel Bernal Suárez (coord.), Agustín Espinosa. Sueños adversos, Canarias: Gobierno de Canarias, 12-13.

Bonet, Juan Manuel (2011): «Óscar Domínguez y Gaceta de Arte. Fichas sobre tres cubiertas de "Óscar X"”, en Isidro Hernández Gutiérrez (comis.) y Maite Martín (coord.), Óscar Domínguez: una existencia de papel, Santa Cruz de Tenerife: TEA Tenerife Espacio de las Artes, 97-116.

Durand, Pascal (2014): «Hombre de letras, escritor, autor. Declinación social de una función simbólica», en Juan Zapata, La invención del autor. Nuevas aproximaciones al estudio sociológico $y$ discursivo de la figura autorial, Medellín: Universidad de Antioquia, 115-128.

Espinosa, Agustín (1980): Textos (1927-1936), Santa Cruz de Tenerife: Aula de Cultura.

Durozor, Gérard (2011): «Le grand ordinaire. Elogio de una complicidad», en Isidro Hernández Gutiérrez (comis.) y Maite Martín (coord.), Óscar Dominguez: una existencia de papel, Santa Cruz de Tenerife: TEA Tenerife Espacio de las Artes, 289-322.

Espinosa, Agustín (1986): «Textos inéditos», en José Miguel Pérez Corrales, Agustín Espinosa, entre el mito y el sueño, Las Palmas: Cabildo Insular de Tenerife, 651-736.

Espinosa, Agustín (2018): Crimen. Textos 1934-1936, edición de José Miguel Pérez Corrales, Santa Cruz de Tenerife: Insoladas.

Foucault, Michel (1984): «QQué es un autor?», Dialéctica, n. ${ }^{\circ} 16,4-18$.

Gómez Gutiérrez, Beatriz (2008): Les mythes et leurs métamorphoses dans l'œuvre d'Agustín Espinosa (1897-1939), Marie-Claire Zimmermann (dir.), París: Sorbonne Université.

Havard, Robert (2001): The Crucified Mind. Rafael Alberti and the Surrealist Ethos in Spain, Londres: Tamesis.

IzQuIERdo, Eliseo (2019): Encubrimientos de la identidad: seudónimos y otros escondrijos en la literatura, el periodismo y las artes en Canarias, San Cristóbal de La Laguna: Instituto de Estudios Canarios.

Jones, Daffyd W. (2019): The fictions of Arthur Cravan. Poetry, boxing and revolution, Manchester: Manchester University Press.

Letaillieur, François (2011): «Óscar Domínguez y las ediciones de Guy Lévis Mano», en Isidro Hernández Gutiérrez (comis.) y Maite Martín (coord.), Óscar Domínguez: una existencia de papel, Santa Cruz de Tenerife: TEA Tenerife Espacio de las Artes, 137-166.

Meizoz, Jérôme (2004): “Postures” d'auteur et poétique (Ajar, Rousseau, Céline, Houellebecq)», URL: http://www.vox-poetica.org/t/articles/meizoz.html.

Meızoz, Jérôme (2013): «Escribir es entrar en escena: la literatura en persona», en Estudios: Revista de Investigaciones Literarias y Culturales, vol. 42, 253-269. 
Moreno Caballud, Luis (2010): «Las relaciones interartísticas de vanguardia ante lo político. Un estudio sobre "La Gaceta Literaria” (1927-1932)», Revista Canadiense de Estudios Hispánicos, vol. 34, n. ${ }^{\circ} 3,429-449$.

Pérez Corrales, Miguel (1986): Agustín Espinosa, entre el mito y el sueño, tomos I y II, Las Palmas de Gran Canaria: Ediciones del Cabildo Insular de Gran Canaria.

Pérez Corrales, Miguel (2018): «Agustín Espinosa, desde 1936», en José Miguel Pérez Corrales (ed.), Agustín Espinosa, Crimen. Textos 1934-1936, Santa Cruz de Tenerife: Insoladas, 325-346.

Randall, Marilyn (2001): Pragmatic Plagiarism. Authorship, Profit and Power, Toronto: University of Toronto Press.

Robles, Juan de (2015): El culto sevillano, Enrique Suárez Figaredo (ed.), Lemir, n. ${ }^{\circ}$ 19, 637-822.

Salaverría, José María (1928): «La moral del literato», $A B C, 17$ de marzo.

Torres Villarroel, Diego (1966): Visiones y visitas de Torres con Don Francisco de Quevedo por la Corte, Russell P. Sebold (ed.), Madrid: Espasa Calpe.

Zubiaurre, Maite (2014): Culturas del erotismo en España 1898-1939, Madrid: Cátedra. 
